\title{
BREAKING UP DORMANCY OF ADANSONIA DIGITATA L. SEEDS AND REGENERATION OF PLANTLETS FROM STEM NODAL SEGMENTS IN VITRO
}

\author{
Aziza M. Taj Aldin
}

Biology Department, Faculty of Science, Sana'a University, Yemen

\begin{abstract}
In Yemen, there are only three trees of Adansonia digitata L. which is adopted in this study. Natural regeneration and independent germination of Adansonia digitata is poor although it is one of the tallest trees in the world that was recorded to live about 4000 years. Unfortunately, the tree is a subject of extinction. In the present study, the seeds of Adansonia digitata L. were pretreated with full and half strength of hydrochloric, sulfuric and nitric acids for one and/or two hour as a mean of scarification to break the dormancy of the seeds. Seeds were then surface sterilized and allowed to germinate on hormone-free MS basal salts culture medium in vitro. The obtained seedlings were used as a source of nodal segments explants for propagation in vitro. Results of the present study have shown that all of the acid treatments overcame seed dormancy and enhanced seed germination in various degrees. The percentage of seed germination increased from $18.6 \%$ in the control group to $86.6 \%$ using a pretreatment of half strength sulfuric acid for one hour. The germinated seeds grown into seedlings of a mean of 11.1 centimeter after 8 weeks of growth. Stem nodal segments were cultured on agar solidified MS basal salts supplemented with various concentrations of benzyle adenine (BA) and naphthalene acetic acid (NAA). The maximum regenerant shoot length $(15.1 \pm 03 \mathrm{~cm})$ was obtained with $8 \mathrm{mg} / \mathrm{l}$ BA plus $0.5 \mathrm{mg} / \mathrm{l} \mathrm{NAA}$ while The maximum number of leaves per regenernt reached up $(7.2 \pm 0.2)$ using $10 \mathrm{mg} / \mathrm{l} \mathrm{BA}+1.0 \mathrm{mg} / \mathrm{l} \mathrm{NAA}$.The obtained regenerants developed roots on the same culture media. They were acclimatized for one week and then transferred to soil.
\end{abstract}

Keywords: Adansonia digitata L, Seed dormancy, Regeneration, In vitro.

\section{INTRODUCTION}

Adansonia digitata L. (Bombacaceae), native to Africa, is one of the tallest trees in the world and may live for 4000 years. Adansonia is regarded as the "Queen of all carbon storage trees" as the tender roots, tubers, twigs, fruits, seeds, leaves and flowers are all edible and they are common ingredients in traditional dishes in rural areas in Africa (Sundarambal et al., 2015). In its African natural habitats, Adansonia digitata is considered an economically important tree species for rural people and also on the national level because of its medicinal (Kamatou and Vermaak Vilijoen, 2011) and nutritional (Zahrau et al., 2014) uses as well as benefits of the tree as a source of raw material for many other purposes (for example the bark of the tree is used as an anti fire fiber). From various parts of the plant, reasonable amounts of phytochemically active metabolites like steroids, flavonoids, epicatechin, campesterol, Tocopherol, adansonin, amino acids, vitamins and minerals. (Suganth et al., 2014; Jitin et.al.,
2015) has been detected. This may explain why It has been used effectively in the treatment of bronchial asthma, dermatitis, sickle cell anemia, as a diuretic, anti-diabetic, anti-oxidant, anti inflammatory agent, antidote for poison, antibacterial agent, anti viral, anti-trypanosome, as a laxative and also used against diarrhea and dysentery (Donaties et al., 2011; Singh et al., 2013).

Adansonia digitata (which is locally called "Shagarat Al-Ghareeb" in Yemen) is not an endemic tree. The total number of trees found in Yemen by botanists is just 3 (personal communication). There are suggestions that it was occasionally brought up from its natural African habitats to Yemen by Arab traders (Burton, 1969 ). Under the circumstances of Yemen, Adansonia digitata exhibits many problems with regards to flowering, fruiting and accordingly propagation. In India, The tree at present is also facing a crisis of survival and is enlisted as an endangered species in the Red data book with only 30 to 40 trees available (Singh et al., 
2010). In Senegal, N'Doye et al., (2012) also reported that the tree is is now threatened with depletion and worse extinction. Gebauer, et al ., (2002) reported that Adansonia digitata suffers from high risk of extinction because of the lack of its natural regeneration and hence, practical ex situ conservation measures are urgently needed to preserve genetic diversity and maintain multiple specimens. Danthu et al., (1995) reported that Baobab (A. digitata) seeds have very hard seed coats and germination is usually less than 20\%. Dormancy of seeds of Adansonia digitata can be attributed partly to the testa and partly to the pulp. According to Falemara et al., (2013), the restricting factor in germination is due to the fact that the seed coat is impermeable to water. Cultivation of baobab necessitates that the seeds be pre-treated to enhance the accessibility of water and oxygen into the seeds before planting in order to break dormancy and to obtain optimum germination and improve performance for plantation establishment. Several methods, such as wet heat treatment, total or partial seed decoating and scarification of seeds with concentrated acids, herbicides, fungicides and growth regulators has been used to break up seed prmancy.

In vitro regeneration of Adansonia digitata plants via seed culture was carried out by Katsuaki and Sie (2007), Singh et al., (2010) and also from different explants of seedlings by N'Doye et al., (2012). The main objective of the present study is to break up the dormancy of seeds by acid pretreatment and then use the nodal segments of the obtained seedlings as explants for in vitro regeneration.

\section{MATERIALS AND METHODS}

Plant material: The seeds of A. digitata L. were isolated from fruits brought from $\mathrm{Su}-$ dan. The seeds were subjected to viability test through the floatation method. This is based on the observation that sound seeds of most spe- cies sink in water while empty, defective and dead seeds float.

Scarification of seeds: This was carried out by immersing the seeds in full and half strength of hydrochloric acid, sulfuric acid and nitric acid for one or two hours. The seeds were then washed with distilled water several times to get rid of any traces of the acid treatments before in vitro germination via seed culture.

Surface sterilization of seeds: This was carried out according to Chawla, (2003) by submerging the seeds into a solution of $70 \%$ ethanol with continuous and gentle steering for one minute, transferring them to $100 \mathrm{ml}$ conical flask containing $20 \%$ solution of commercial sodium hypochlorite ( $1 \%$ active chlorine) with continuous gentle steering for 15 minutes. The sterilant decanted and the seeds washed with 3 successive rinses of sterile distilled water under aseptic conditions. The seeds were dried between two layers of sterile filter papers in a Petri-dish.

Germination of seeds: This was carried out under aseptic conditions by sawing the seeds on the surface of hormone - free Murashige and Skoog's (1962) basal salts media solidified with $0.8 \%$ agar. Each culture tube contained $30 \mathrm{ml}$ of culture media and one seed. Germination was allowed to take place at room temperature.

Regeneration : The obtained seedlings from germination experiment were used as sources of stem nodal segments. The nodal segments were aseptically cultured on MS culture media supplemented with BA $(0,2,4,6,8,10 \mathrm{mg} / 1$ in combination with NAA $0.0,0.5,1.0 \mathrm{mg} / \mathrm{l})$. The cultures were kept at room temperature, photoperiod of 16 hours light, 8 hours dark.

\section{Statistical analysis}

Germination of seeds and response of nodal segments to various hormonal treatments was calculated as \%. Shoot length and number of leaves per regenernt was calculated as a mean of 10 readings \pm standard error. 
Breaking up dormancy of Adansonia digitata L. seeds and

Table (1): Effect of acid pretreatments and soaking periods on germination of Adansonia digitata seed germination

\begin{tabular}{|c|c|c|c|c|c|c|c|c|c|c|c|c|c|c|}
\hline \multirow{3}{*}{\multicolumn{2}{|c|}{\begin{tabular}{|c|} 
Treatment \\
Strength \\
Period (hrs)
\end{tabular}}} & \multirow{4}{*}{ 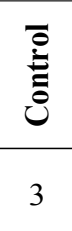 } & \multicolumn{4}{|c|}{ Hydrochloric } & \multicolumn{4}{|c|}{ Sulfuric } & \multicolumn{4}{|c|}{ Nitric } \\
\hline & & & \multicolumn{2}{|c|}{$\begin{array}{c}\text { Full } \\
\text { strength }\end{array}$} & \multicolumn{2}{|c|}{$\begin{array}{c}1 / 2 \\
\text { Strength }\end{array}$} & \multicolumn{2}{|c|}{$\begin{array}{c}\text { Full } \\
\text { strength }\end{array}$} & \multicolumn{2}{|c|}{$\begin{array}{c}1 / 2 \\
\text { strength }\end{array}$} & \multicolumn{2}{|c|}{$\begin{array}{c}\text { Full } \\
\text { strength }\end{array}$} & \multicolumn{2}{|c|}{$\begin{array}{c}1 / 2 \\
\text { strength }\end{array}$} \\
\hline & & & \multirow{2}{*}{$\begin{array}{l}\text { I } \\
3\end{array}$} & \multirow{2}{*}{$\frac{\text { II }}{7}$} & \multirow{2}{*}{$\begin{array}{c}\mathbf{I} \\
12\end{array}$} & \multirow{2}{*}{$\frac{\text { II }}{5}$} & \multirow{2}{*}{$\begin{array}{l}\text { I } \\
9\end{array}$} & \multirow{2}{*}{20} & \multirow{2}{*}{18} & \multirow{2}{*}{ II } & \multirow{2}{*}{$\begin{array}{l}\text { I } \\
4\end{array}$} & \multirow{2}{*}{ II } & \multirow{2}{*}{ I } & \multirow{2}{*}{$\begin{array}{l}\text { II } \\
6\end{array}$} \\
\hline ग्र & 10 days & & & & & & & & & & & & & \\
\hline 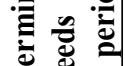 & 20 days & 6 & 18 & 21 & 23 & 22 & 14 & 12 & 34 & 11 & 25 & 13 & 16 & 12 \\
\hline 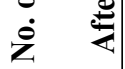 & 30 days & 2 & 4 & 0 & 1 & 0 & 8 & 4 & 0 & 2 & 1 & 0 & 0 & 0 \\
\hline \multicolumn{2}{|c|}{$\begin{array}{l}\text { Total No. of } \\
\text { germinated seeds } \\
\text { per } 60\end{array}$} & 11 & 25 & 28 & 36 & 27 & 31 & 36 & 52 & 25 & 30 & 29 & 20 & 18 \\
\hline \multicolumn{2}{|c|}{$\%$ of germination } & 18.3 & 41.6 & 46.6 & 60.0 & 45.0 & 51.6 & 60.0 & 86.6 & 41.6 & 50.0 & 48.3 & 33.3 & 30. \\
\hline
\end{tabular}

Table (2): Shoot length of A. digitata seedlings germinated in vitro on MS hormone free culture medium

\begin{tabular}{|l|c|c|c|c|}
\hline Growth period in weeks & 2 & 4 & 8 & 12 \\
\hline Shoot length in cm. & 4.3 & 6.1 & 8.5 & 11.1 \\
\hline
\end{tabular}

Table (3): Effect of various hormonal concentrations on number of nodal segments which showed bud development, height of renenerants developed $(\mathrm{cm})$ and number of leaves per regenerant. Each value is a mean of 10 readings \pm standered error. Measurements were taken after one month of growth on MS.

\begin{tabular}{|c|c|c|c|c|c|c|c|}
\hline \multicolumn{2}{|c|}{ NAA mg/l. } & $\mathbf{0}$ & 2 & 4 & 6 & 8 & 10 \\
\hline \multirow{3}{*}{$\theta$} & No.,of explants responded/10 & $1 / 10$ & $0 / 10$ & $4 / 10$ & $4 / 10$ & $8 / 10$ & $8 / 10$ \\
\hline & Regenerant height $(\mathrm{cm})$ & f..... & ....... & $6.1 \pm 0.1$ & $8.2 \pm 0.3$ & $10.1 \pm 02$ & $13.8 \pm 0.3$ \\
\hline & Number of leaves & $\ldots$ & $2 \ldots \ldots \ldots$ & $3.0 \pm 0.3$ & $3.3 \pm 0.2$ & $5.2 \pm 0.3$ & $6.1 \pm 0.5$ \\
\hline \multirow{3}{*}{$\dddot{n}$} & No.,of explants responded/10 & $0 / 10$ & $2 / 10$ & $4 / 10$ & $4 / 10$ & $8 / 10$ & $8 / 10$ \\
\hline & Regenerant height $(\mathrm{cm})$ & $\ldots$ & $4.5 \pm 0.2$ & $11.1 \pm 0.6$ & $10.8 \pm 0.5$ & $15.1 \pm 03$ & $14.3 \pm 0.5$ \\
\hline & Number of leaves & $\ldots$ & $2.9 \pm 0.1$ & $5.3 \pm 0.3$ & $5.9 \pm 0.1$ & $8.8 \pm 0.5$ & $7.2 \pm 0.2$ \\
\hline \multirow{3}{*}{$\stackrel{\ominus}{-}$} & No.,of explants responded/10 & $0 / 10$ & $0 / 10$ & $4 / 10$ & $6 / 10$ & $6 / 10$ & $10 / 10$ \\
\hline & Regenerant height $(\mathrm{cm})$ & ....... & 0 & $6.8 \pm 0.1$ & $13.3 \pm 0.2$ & $13.5 \pm 03$ & $14.3 \pm 0.2$ \\
\hline & Number of leaves & ........ & 0 & $3.7 \pm 0.4$ & $8.2 \pm 0.3$ & $6.3 \pm 0.5$ & $7.2 \pm 0.2$ \\
\hline
\end{tabular}
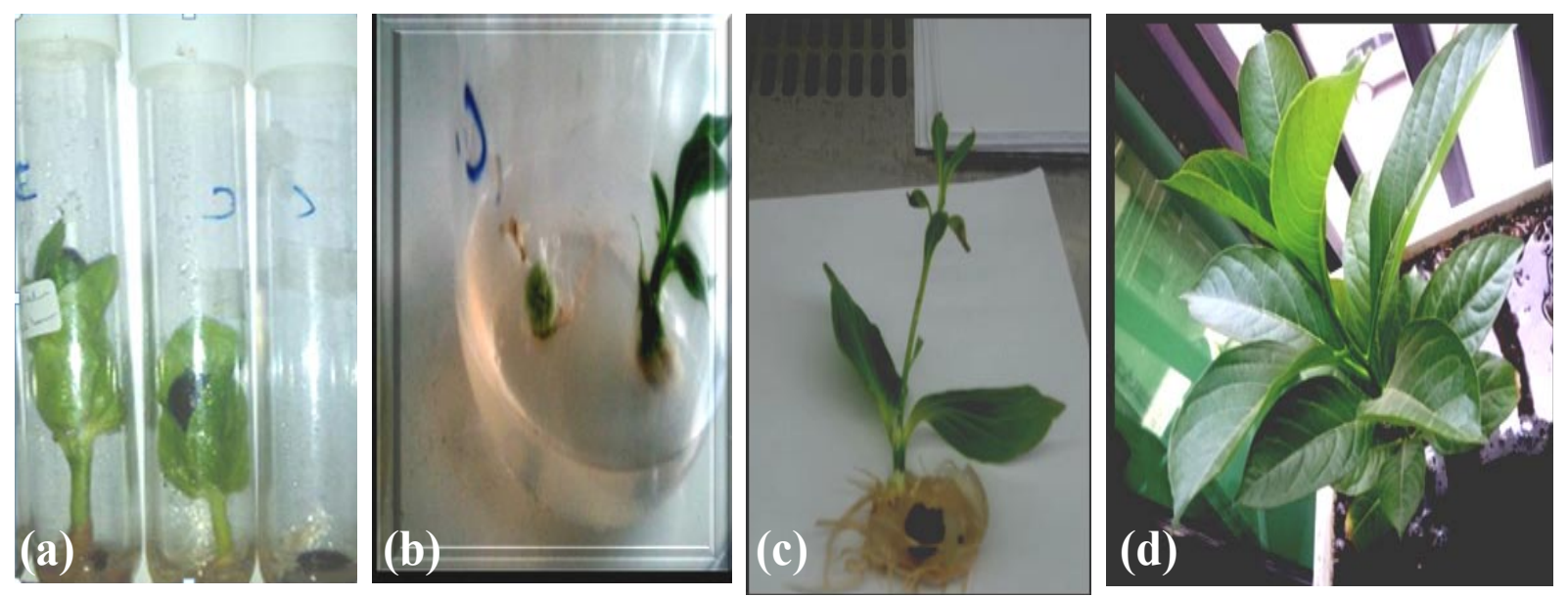

Figure (1): Regeneration of A. digitata in vitro. (a) Germination of seeds on MS, (b) Lateral bud growth from nodal segments, (C) Rooted plantlets, (d) Acclimatized potted plant. 


\section{RESULT AND DISCUSSION}

From the results of the present study (table 1) that the percentage of germination of control group seeds was $18.3 \%$. This result may agree and confirm the work done by Danthu et al., (1995) who reported that Baobab seeds have very hard seed coats and germination is usually less than 20\%. Esenowo, (1991), also asserted that dormancy in seeds of Adansonia digitata (L.) can be attributed partly to the testa and partly to the pulp. Falemara et al., (2013) reported that the restricting factor in germination is due to the fact that the seed coat is impermeable to water and thus, the cultivation of baobab seeds necessitates a pre-treatment step to enhance the accessibility of water and oxygen into the seeds before planting, in order to break dormancy .

Results obtained in this study ( table 1) shows that all acid pretreatments treatments could break up seed dormancy and enhance seed germination over the control group seeds. The best percentage of seed germination reached up $86 \%$ in response to treatment with half strength sulfuric acid for one hour, a result which may agree with the results obtained by Esenowo, (1991) who reported that, the most effective method of A. digitata seed pretreatment was scarification with $\mathrm{H} 2 \mathrm{SO} 4$ where the germination percentage reached up to $98 \%$. In another study carried out by Danthu, et al., (1995), it was found that the treatment of baobab seeds with concentrated sulphuric acid for 6-12 hrs led to germination of more than $90 \%$ of the seeds within twenty days of culturing, a result which may be also more or less similar to the results obtained in this study. It is to be remembered also that sulphuric acid pretreatment of Afzelia African seeds reduced the dormancy period and yielded a more uniform and regular germination by Amusa (2011). Results of the present study (table2) shows that the germinated seeds could grow to reach up a height of $11.1 \mathrm{~cm}$ after 12 weeks on hormone free MS culture media which was renewed every 4 weeks.

The results obtained in this study, as illustrated in table (3), have shown that the development of lateral buds into shoots needed the presence of benzyl adenine as a must was directly affected by the cytokinin/auxin ratio in the culture medium. The concentration of $10 \mathrm{mg} / \mathrm{l}$ of benzyl adenine in combination with $1 \mathrm{mg} / 1$ of NAA resulted in a response of 100 percent bud development where all the tested nodal segments explants produced shoots from their lateral buds. The number of leaves per single shoot ranged from $2.9 \pm 0.1$ ( using $2 \mathrm{mg} / 1 \mathrm{BA}+0.5 \mathrm{mg} / 1 \mathrm{NAA}$ ) to $7.2 \pm 0.2$ (using $10 \mathrm{mg} / \mathrm{l} \mathrm{BA}+1.0 \mathrm{mg} / \mathrm{l} \mathrm{NAA})$. The maximum regenerant height $(15.1 \pm 03 \mathrm{~cm})$ was obtained with $8 \mathrm{mg} / 1 \mathrm{BA}$ plus $0.5 \mathrm{mg} / 1 \mathrm{NAA}$. The obtained regenerants directly developed root morphogenesis without any need to transfer them to a rooting medium. This probably due to the presence of auxin in the shoot growth media used. The first attempt of regeneration of A. digitata from stem nodal segments were carried out by Katsuaki and Sie (2007) where they reported that Shoots were obtained from nodal segments of in vitro germinated $\mathrm{A}$. digitata cultured on $1 / 2 \mathrm{LP}$ medium containing $10 \mu \mathrm{M}$ BAP and that rooted plantlet was regenerated on half-strength woody plant medium containing $3.5 \mu \mathrm{M}$ IBA and 0.32 $\mu \mathrm{M} N A A$ for the first time. Successful regeneration trial was also done by N'Doye et al., (2012) from different explants of seedlings and Rolli et al., (2014) via enhancing axillary bud multiplication. Rolli et al., (2014) In vitro shoot multiplication was achieved by enhanced axillary bud proliferation of sterilized two-node segments. Bud break was dependent on cytokinin supply (a result that was also clearly observed in the pressent study) but the combination of 1.0 or $10.0 \mu \mathrm{M}$ zeatin riboside and $10.0 \mu \mathrm{M}$ indole-3-butyric acid (IBA) increased the formation of microshoots after 8 weeks of culture. Regenerated microshoots rooted successfully in in vitro nutrient medium containing $10.0 \mu \mathrm{M}$ IBA and normally grew in a greenhouse after acclimatization. Some of the steps of the regeneration process of A. digitata can be seen in figure (1).

\section{CONCLUSION}

Adansonia digitata L. is an endangered plant not only in the countries where it was introduced in but also in its natural habitat due to overharvesting, high level of seed dormancy and poor regeneration and slow growth. In Yemen, there are only three trees and in all India just 30-40 
trees. Adansonia digitata (which is called by the public in Yemen "Shagart El-Ghareeb") is one of the tallest trees in the world that was recorded to live about 4000 years. There are many publications which mentioned that almost every part of the tree is edible and very rich in its own nutritive and medicinal constituents. The tree is being used for many other purposes; even the bark of the tree represents an excellent anti fire fiber. In the present study the dormancy of seeds of Adansonia digitata L. was successfully broken up by pretreatment with full and half strength of hydrochloric, sulfuric and nitric acids for one and/or two hours. The obtained seedlings were used as a source of nodal segments explants for propagation in vitro. Regeneration of plantlets from the nodal segments of the obtained seedlings was carried out on MS culture medium using benzyl adenine as a cytokinin (from 2-10 $\mathrm{mg} / \mathrm{l})$ with or without the addition of naphthelene acetic acid (0.5-1.0) as an auxin. After the obtained regenerants had reached suitable height and developed roots, they were acclimatized and transferred to soil successfully. The results obtained in this study may play a role in saving and spreading this tree in Yemen for local use and probably, improvement of country national income.

\section{REFERENCES}

Amusa, T.O. (2011): Effects of three pre-treatment techniques on dormancy and germination of seeds of Afzelia Africana. Jour. Hort. Forest. 3(4): 96-103.

Danthu, P., Roussel, J., Gaye, A. and El Mazzoudi, E. H. (1995): Baobab ( Adansonia digitata L.) seed pretreatments for germination improvement. Seed Sci. Technol. 23:469-475.

Donaties, K., Hagretou, S., Brehima D., Clarisse, S. and Mamoudou, H. (2011): A Review Of Baobab (Adansonia digitata) Products: Effect Of Processing Techniques, Medicinal Properties And Uses. Afric. Jour. Food Sci. 5(16):833- 844.

Esenowo, G. J. (1991): Studies on germination of Adansonia digitata seeds. Jour. Agricul. Sci., 117(1): 81-84.

Falemara, B. C., Nwadike, C. and Obashola, E. O. (2013): Germination Response of Baobab Seed (Adansonia Digitata L.) as Influenced by Three PreTreatment Techniques. Forest Industry in a Dynamic Global Environment: Proceedings of the 35 Annual Conference of Forestry Association of Nigeria, Sokoto, Sokoto State. pp $44-55$.
Gebauer, J., El-Siddig, K., and Ebert G. (2002): Baobab (Adansonia digitata L.): a Review on theMultipurpose Tree with Promising Future in the Sudan. Gartenbauwissenschaft, 67(4):155-160.

Jitin, R., Jain, M., Singh, S., kamal, R., Anuradha, N., Jupta, A. and Merityungai, S. (2015): Adansonia digitataa L. (baobab); A Review of traditional information and taxonomic description. Asian Pak., Jour. Trop. Biomed. 5(1): 79-84.

Kamatou GPP, Vermaak Vilijoen AM. An updated review of Adansonia digitata: a commercially important African tree. South African journal of Botany. 2011; 77:908919. 3. The Wealth of India. 2003, 1a:71-73.

Katsuaki, I and Sie, K, (2007). In vitro culture of an African multipurpose tree species: Adansonia digita L. Propag. Orna. Pl., 7(2).

Murashige, T. and Skoog, F. (1962): A revised medium for rapid growth and bio-assays with tobacco tissue cultures. Physiol. Pl. 15(3): 473-497.

N'doye, A., Sambe, M. and Mame, O. (2012): Propagation Of African Baobab (Adansonia Digitata L., Bombacoideae, Malvaceae) Germplasm Through In Vitro Cloning. Advances in Environ. Biol., 6(10): 2749-2757.

Rolli, E; Brunoni, F. and Bruni, R. (2014): An optimized method for in vitro propagation of African baobab (Adansonia digitata L.) using two-node segments, Plant Biosystems - An International Journal Dealing with all Aspects of Plant Biology: Official Journal of the Societa Botanica Italiana, DOI: 10.1080/ 11263504.2014.991362

Saikou, E., Kabura, B. and Huang, W. (2008): Effects of some seed pretreatments onemergence of Acacia senegal (L.). World Jour. Agricult. Sci. 4(2): 213-219.

Singh S., Parasharami V. and Rai, S. (2013): Medicinal Uses of Adansonia digitata: An Endangered Tree Species. Jour. Pharmaceut. Scienti. Innov. 2(3):14-16.

Singh, S., Rai, S. and Shagufta K. (2010): In vitro seed germination of Adansonia digitata L.: An endangered medicinal tree. Nanobiotechnica Universale. 1(2): 107112.

Suganth S., Ranjeetha C., Shasi R., Varsha P. (2014): Preliminary Phytochemical Evaluation of In vivo and In vitro plant parts of Adansonia digitata, an endangered medicinal tree. Universal jour. Pharm. 3:34-40.

Sundarambal M, Muthusamy P, Radha R, Jerad Suresh A. (2015). A review on Adansonia digitata Linn. Jour. Pharmacog. Phytochem. 4(4):12-16.

Zahrau, B., Abdul Karim, S., Mohd G. and Roselina K.(2014). Baobab Tree (Adansonia digitata L.) parts: Nutrition Applications in Food and Uses in Ethno Medicine - A Review Austin Publishing Group. 1(3):1011. 


\section{عزيزة مصلح تاج الدين}

\section{قسم البيولوجى - كلية العلوم - جامعة صنعاء ـ اليمن ملاج}

إن نبات أدانسونبا ديجيتاتا نبات معرض للخطر والإنقر اض ليس فقط فى البلدان التى أدخل إليها ولكن أيضا في موطنه

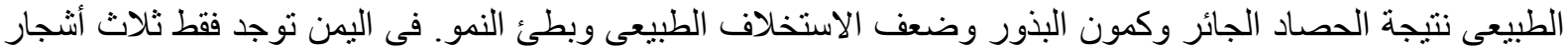

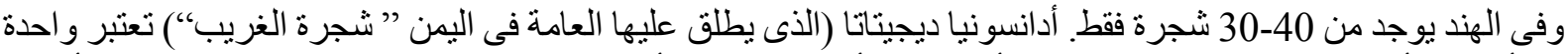

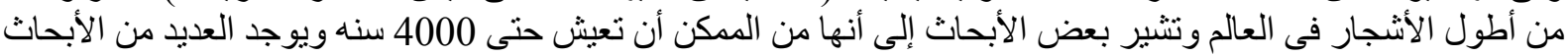

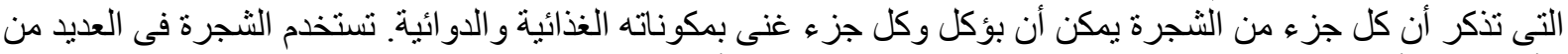

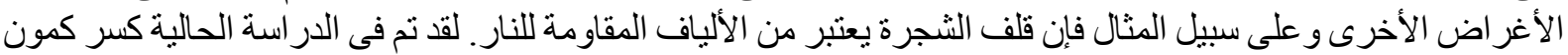

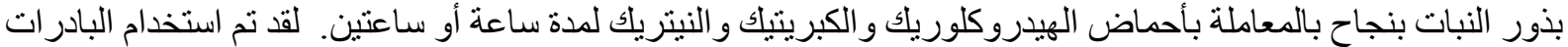

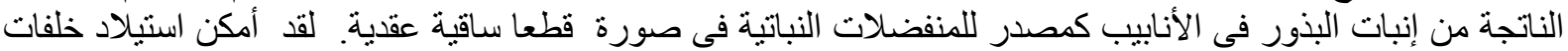

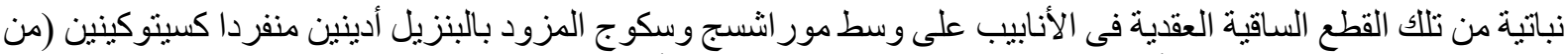

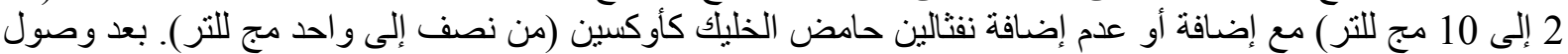

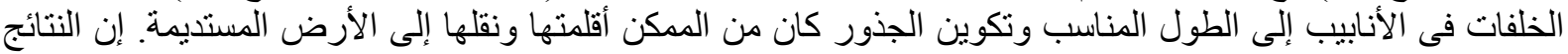

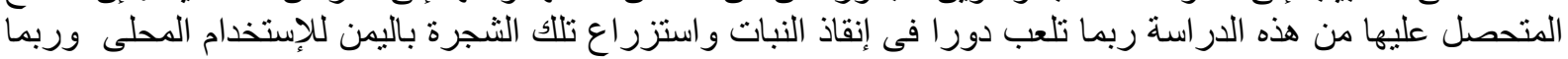

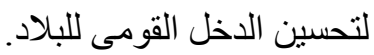

